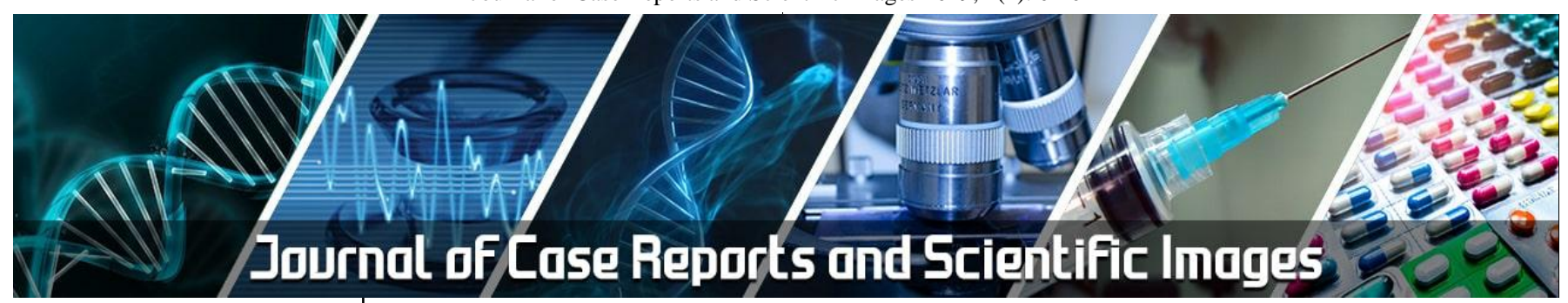

E-ISSN: 2708-0064 P-ISSN: 2708-0056 www.allcasereports.com JCRSI 2019; 1(1): 01-02 Received: 02-11-2018 Accepted: 05-12-2018

Javier Cassel

Department of Scientific, European Institute of Science AB, Sweden
Corresponding Author: Javier Cassel

Department of Scientific, European Institute of Science AB, Sweden

\section{A case of snake bite in 20 years old male patient}

\section{Javier Cassel}

DOI: https://doi.org/10.33545/27080056.2019.v1.i1a.1

\begin{abstract}
Venomous snakebite is a significant cause of global morbidity and mortality. Venomous snakes are found almost throughout the world. We reported a case of snake bite in 20 years old male patient managed conservatively.
\end{abstract}

Keywords: Venomous snakebite, morbidity, mortality

\section{Introduction}

Venomous snakebite is a significant cause of global morbidity and mortality. Venomous snakes are found almost throughout the world ${ }^{[1]}$. Most data suggest that they cause in excess of 3 million bites/year with $>150,000$ deaths, particularly in rural tropical areas. At least 421,000 cases of envenoming and 20,000 deaths occur every year worldwide due to snakebite ${ }^{[2]}$.

There are many species of snakes prevalent in Egypt; these include Elapidae (Naja haje [Nh], Naja nigricollis [Nn], Naja pallida, and Walterinnesia aegyptia [Wa]), Viperidae (Cerastes cerastes, Cerastes vipera, Pseudocerastes persicus fieldi, Echis pyramidum, Echis coloratus, and Echis carinatus), Typhlopidae (Ramphotyphlops braminus), Boidae (Eryx jaculus), and Colubridae ${ }^{[3,4]}$.

The incidence of snake bite rises substantially in the monsoon season. The case being reported too occurred during this season ${ }^{[5]}$. Venomous snakes are classified into two important families, elapidae and viperidae. Elapidae have short, permanently erect fangs and include cobra, krait, coral snakes and sea snakes. Cobra venom acts post synaptically while krait venom acts pre synaptically. Viperidae on the other hand have long fangs folded up against the upper jaw which are erected when the snake strikes ${ }^{[6]}$.

This family consists of snakes like the typical vipers (Viperinae) and the pit vipers (Crotalinae). The Crotalinae have special sense organ called the pit organ situated between the nostril and the eye to detect warm blooded prey. Snake bites are more common after rains, after floods, during harvest and at night ${ }^{[7]}$. We reported a case of snake bite in 20 years old male patient.

\section{Case report}

A 20 years old male patient brought to the department of General Medicine complaint of swelling over face since 2 hours. History revealed that swelling started from upper lip and progressed to involve complete face, associated with severe pain. It started in the night when patient got up from sleep due to some sharp pain over upper lip.

Oral examination revealed snake bite mark over upper lip. GCS score found to be E4M3V2. General examination showed icterus, cyanosis, pitting oedema all over face. Patient was subjected to blood investigations with showed urea $25 \mathrm{mg} / \mathrm{dl}$, creatinine $1.4 \mathrm{mg} / \mathrm{dl}, \mathrm{Na}+146$ $\mathrm{m}$ eq/L, K gm\%, WBC 20,480/cu mm, Neutrophils 92\% and Lymphocytes 8\%, platelet 1.60 lakh/comm., Prothrombin time 40 seconds, INR 3.2 and APTT $52 \mathrm{sec}$. Patient was treated on emergency basis and we started IV crystalloids and IV antibiotics. Suspicion of snake bite 10 vials of ASV was given. 2 units of FFP were given. On third day oedema over face reduced associated with blackening of skin below eyes. On fourth day, Hematological parameters improved and oedema further subsided. Patient recovered well within 7 days and he was discharged in a stable condition. 


\section{Discussion}

Snakebite is an ancient medical problem in Egypt. An ancient Egyptian Papyrus kept at the Brooklyn Museum in New York illustrates a systematic description of 38 snakes and their bites with many remedies and a few spells for those bitten by snakes ${ }^{[8]}$.

Venomous snakes mainly have hemotoxic (Viperidae) and/or neurotoxic (Elapidae) venom. Coagulopathy is a common and serious manifestation of severe Viperidae snake envenoming. Neurotoxic snake envenoming, mainly due to the Elapidae family, is one of the most important causes of snakebite fatality ${ }^{[9]}$. Different protocols exist to manage snakebite as suggested by the World Health Organization (WHO), Goldfrank's Toxicologic Emergencies textbook, and Haddad and Winchester's (Haddad) Clinical Management of Poisoning and Drug Overdose textbook. These protocols are different from each other regarding management of the patients and even in the determination of the severity of envenomation ${ }^{[10]}$.

Antisnake venom (ASV) is mostly effective when used at the appropriate dosage and indication. There is still a conflicting advice among physicians about the appropriate dosing, frequency of administration, and duration of therapy [11]. Recommendation of a universal initial dose is a difficult issue as there is no well-known end point available in antivenom administration against envenoming snakebites [12]. Furthermore, the neutralizing power of antivenoms varies according to the type of antivenom and from batch to batch. Even when the venom is neutralized by antivenom, there may be a delay before the recovery of the coagulopathy state. Evidence of envenomation is the only indication of ASV administration ${ }^{[13]}$. We reported a case of snake bite in 20 years old male patient.

Gouda et al. ${ }^{[14]}$ investigated local snakebites presentations, management, prognosis, and the effect of the polyvalent antivenom, locally produced by the Holding Company for Biological Products and Vaccines (VACSERA). A total of 87 snakebites caused by venomous and nonvenomous species were recorded. Most cases were middle-aged males. Most cases presented in summer and in the evening time. Two major groups of venomous Egyptian snakes were identified, Viperidae and Elapidae species, based on history, characteristic symptoms, and laboratory findings. Most snakebites (56 cases) were reported to be non-venomous bites $(64.4 \%)$. Twenty- one cases $(24.1 \%)$ of snakebites were reported to be venomous bites by Elapidae snakes and 10 cases $(11.5 \%)$ were reported to be venomous bites by Viperidae snakes. Antivenom was administered before referral to $37(42.5 \%)$ of cases, and 19 only of them were victims of venomous snakes. Thirty-six $(41.3 \%)$ patients received antivenom during admission including all cases of the venomous bites and $8.9 \%$ of nonvenomous bites' cases.

\section{Conclusion}

Authors found that cases of snake bite are increasing day by day. Careful and speedy investigation may save the life of the person.

\section{References}

1. Seddik SS, Wanas S, Helmy MH, Hashem M. Cross neutralization of dangerous snake venoms from Africa and the Middle East using the VACSERA polyvalent antivenom. Egyptian Organization for Biological Products \& Vaccines. J Nat Toxins. 2002; 11:329- 35.
2. Allam AA, Abo- Eleneen RE. Scales microstructure of snakes from the Egyptian area. Zoology Sci. 2012; 29:770-5.

3. Wahby AF, Abdel-Aty AM, El-Kady EM. Purification of hemorrhagic SVMPs from venoms of three vipers of Egypt. Toxicon. 2012; 59:329- 37.

4. Nunn JF, John F. Ancient Egyptian Medicine. Paperback Edition. Norman: University of Oklahoma Press, 2002.

5. Whyte I, Buckley N. Antivenom update. Aust Prescr 2012; 35:152-5.

6. Milani Júnior R, Jorge MT, de Campos FP, Martins FP, Bousso A, Cardoso JL et al. Snake bites by the jararacuçu (Bothrops jararacussu): Clinicopathological studies of 29 proven cases in São Paulo State, Brazil. QJM 1997; 90:323-34.

7. Isbister GK, Duffull SB, Brown SG. ASP Investigators. Failure of antivenom to improve recovery in Australian snakebite coagulopathy. QJM 2009; 102:563-8.

8. WHO/SEARO guidelines for the clinical management of snake bites in the Southeast Asian region. Southeast Asian J Trop Med Public Health. 1999; 30 Suppl 1:185.

9. Lewis RL, Gutmann L. Snake venoms and the neuromuscular junction. Semin Neurol. 2004; 24:175-9.

10. Rivière G, Choumet V, Audebert F, Sabouraud A, Debray M, Scherrmann JM, et al. Effect of antivenom on venom pharmacokinetics in experimentally envenomed rabbits: Toward an optimization of antivenom therapy. J Pharmacol Exp Ther. 1997; 281:1-8.

11. Gouda AS, Elnabarawy NA, Badawy SM. A study of snakebite envenomation cases admitted to egyptian national poisoning center. Acta Med Int. 2017; 4:34-40. 